\title{
LAS MODIFICACIONES AL CÓDIGO DE PROTECCIÓN Y DEFENSA DEL CONSUMIDOR EN EL PERIODO PARLAMENTARIO 2011-2016 Y LAS MODIFICACIONES QUE QUEDARON PENDIENTES
}

\author{
Karolina Kira Kriete Urruchi*
}

\section{RESUMEN}

El presente artículo aborda las modificaciones del Código de Protección y Defensa del Consumidor, aprobado por Ley 29571 en el año 2010 y que fuera modificado en el último quinquenio por las leyes 29888 y 30046 en los años 2012 y 2013 respectivamente. Se parte por analizar los antecedentes legislativos que dan origen a la primera modificatoria del Código referido a la transparencia de la información y las modificaciones contractuales en los servicios financieros, para explicar posteriormente los alcances y trascendencia del mismo. Así también se hace un análisis de los antecedentes legislativos que dan origen a la segunda y última modificatoria del Código referido a la protección al usuario del servicio de transporte en tramos múltiples. Finalmente, se detallan los dictámenes de proyectos de ley presentados en el Periodo Parlamentario 2011-2016 que pretendieron modificar el Código de Protección y Defensa del Consumidor y que quedan como tarea pendiente para el Periodo Parlamentario 20162021.

\section{ABSTRAC}

This paper focuses on the amendments to the Consumer Protection and Defense Code, adopted by Act 29571 in 2010, as amended in the last five years by Acts 29888 and 30046 in 2012 ans 2013, respectively. The paper begingd by reviewing the legislative background that led to the first amendment to the Code regarding transparency of information and contractual changes lo financial services. It the explains the scope and significance of such amendments. It also reviews the legislative background that led to the second and final amendmenst regarding the protection of multi-leg transport service users. Finally, the asricle discusses the opinions to the bills introduced during the 2011-2016 parliamentary term that sought to amend the Consumer Protection and Defense Code and that remain as pending tasks for the 2016-2021 parliamentary term.

\section{PALABRAS CLAVES:}

Código de Protección y Defensa del Consumidor. Proyecto de Ley. Derecho de Información. Libre Elección. Libro de Reclamaciones. Bienes y servicios inmobiliarios. Servicio de Transporte. Conciliación de Consumo. Servicios Financieros.

\section{KEYWORDS:}

Code of protection and consumer. Right to information. Complaints book. Consumer conciliation. Financial services

* Abogada, por la Universidad Femenina del Sagrado Corazón (UNIFÉ) encargada de la Secretaría Técnica de la Comisión de Defensa del Consumidor y Organismos Reguladores de los Servicios Públicos del Congreso de la República desde Agosto de 2011 a Julio de 2016. 


\section{INTRODUCCIÓN}

El Código de Protección y Defensa del Consumidor (CPDC), en adelante el Código, Ley 29571, publicado el 02 de setiembre de 2010, trajo al espectro normativo peruano avances en materia de la protección al consumidor, destaca sobre todo la inclusión de políticas públicas que fueron consideradas por primera vez en un texto normativo de la trascendencia de un código como conjunto de acciones de los poderes públicos, destacando las políticas de prevención, de protección y de promoción de los derechos de los consumidores, no solamente para prevenir las situaciones de conflicto sino también para tutelar los derechos de los consumidores y que éstos tengan una participación individual o colectiva en la defensa de sus derechos. La finalidad del Código no se limitó a que los consumidores accedan a productos y servicios idóneos y a reducir la asimetría informativa, sino que también gocen de los derechos y los mecanismos efectivos para su protección, y que el Estado prevenga, corrija y elimine las conductas y prácticas que afecten sus legítimos intereses. En esta línea de ideas en el periodo legislativo se presentaron en la Comisión de Defensa del Consumidor y Organismos Reguladores de los Servicios Públicos del Congreso de la República (en adelante la Comisión) 164 iniciativas legislativas de los cuales 27 fueron proyectos de ley que tuvieron el objeto de modificar determinados artículos del Código (CPDC).
Este significativo número de proyectos de ley nos indica que los parlamentarios de la legislatura 2011-2016 vieron la necesidad de modificar ciertos artículos del Código (CPDC), de éstos apenas 3 proyectos de ley que se acumularon en dos dictámenes se convirtieron en leyes que modificaron los artículos 66.7, 82, 83, 84 y 94 del Código (CPDC).

En las siguientes líneas analizaremos los antecedentes legislativos que dan origen a estas modificaciones al Código (CPDC) referido a la transparencia de la información y las modificaciones contractuales en los servicios financieros, Así como a la protección al usuario del servicio de transporte en tramos múltiples, para luego explicar los alcances y trascendencia de las modificaciones.

Finalmente, es necesario analizar los dictámenes de los proyectos de ley presentados en el Periodo Parlamentario 2011-2016 que pretendieron modificar el Código de Protección y Defensa del Consumidor y que no fueron agendados en las sesiones plenarias del mismo periodo legislativo y que quedarían como posible tarea pendiente para el Periodo Parlamentario 2016-2021.

\section{LA PRIMERA MODIFICA- TORIA: TRANSPARENCIA DE LA INFORMACIÓN Y LAS MODIFICACIONES CONTRACTUALES EN LOS SERVICIOS FINANCIEROS}

El Estado defiende el interés de los Consumidores y usua- rios. Para tal acto garantiza el derecho a la información sobre los bienes y servicios que se encuentra en el Mercado, señala nuestra Constitución. ${ }^{1}$ También establece que el Estado facilita y vigila la libre competencia en el mercado, no obstante combate el Monopolio'.

Las empresas del sistema financiero están facultadas para señalar libremente las tasas de interés, comisiones y gastos para sus operaciones activas y pasivas y servicios, las tasas de interés son supervisadas por el Banco Central de Reserva.

El Código estableció que para las operaciones de crédito activas, se incluyeran los costos asociados, sin embargo no se dio esta misma lógica para las operaciones con tarjetas de crédito o créditos revolventes. En ese entonces ${ }^{3}$ el argumento del legislador fue que sería muy difícil o casi imposible informar acerca de los costos totales, incluidas las comisiones, en tanto que éstos podrían variar de operación en operación, dependiendo del comportamiento crediticio de cada usuario.

El Reglamento de Transparencia de información y disposiciones aplicables a la contratación con usuarios del sistema financiero, aprobado mediante la Resolución 17652005/SBS establecía que en las tarjetas de crédito, hasta antes de la dación de la modificación del Código sólo se informaba la Tasa Efectiva Anual (TEA), más no la

Artículo 65 de la Constitución Política del Perú.

Artículo 61 de la Constitución Política del Perú.

Debates del Código del Consumidor, Comisión de defensa del Consumidor de la Legislatura 2009-2010 
Tasa de Costo Efectivo Anual (TCEA), dado que una persona cuando adquiere un crédito, tiene la idea de que sólo pagará lo que le han informado o lo que ve en el momento de adquirir el préstamo, luego al recibir su estado de cuenta se daba con la sorpre- sa de otro monto mayor al que había planificado.

Los Proyectos de Ley 809/2011CR y 810/2011CR pretendieron dar solución a esta situación que afectaba la economía de los consumidores de servicios financieros, dado que en la TEA no estaban incluidos las comisiones, portes y otros conceptos. Dada la distorsión en la información que se daba a los consumidores que resultaba errada y hasta en algunos casos engañosas, conforme se muestra en el siguiente cuadro:
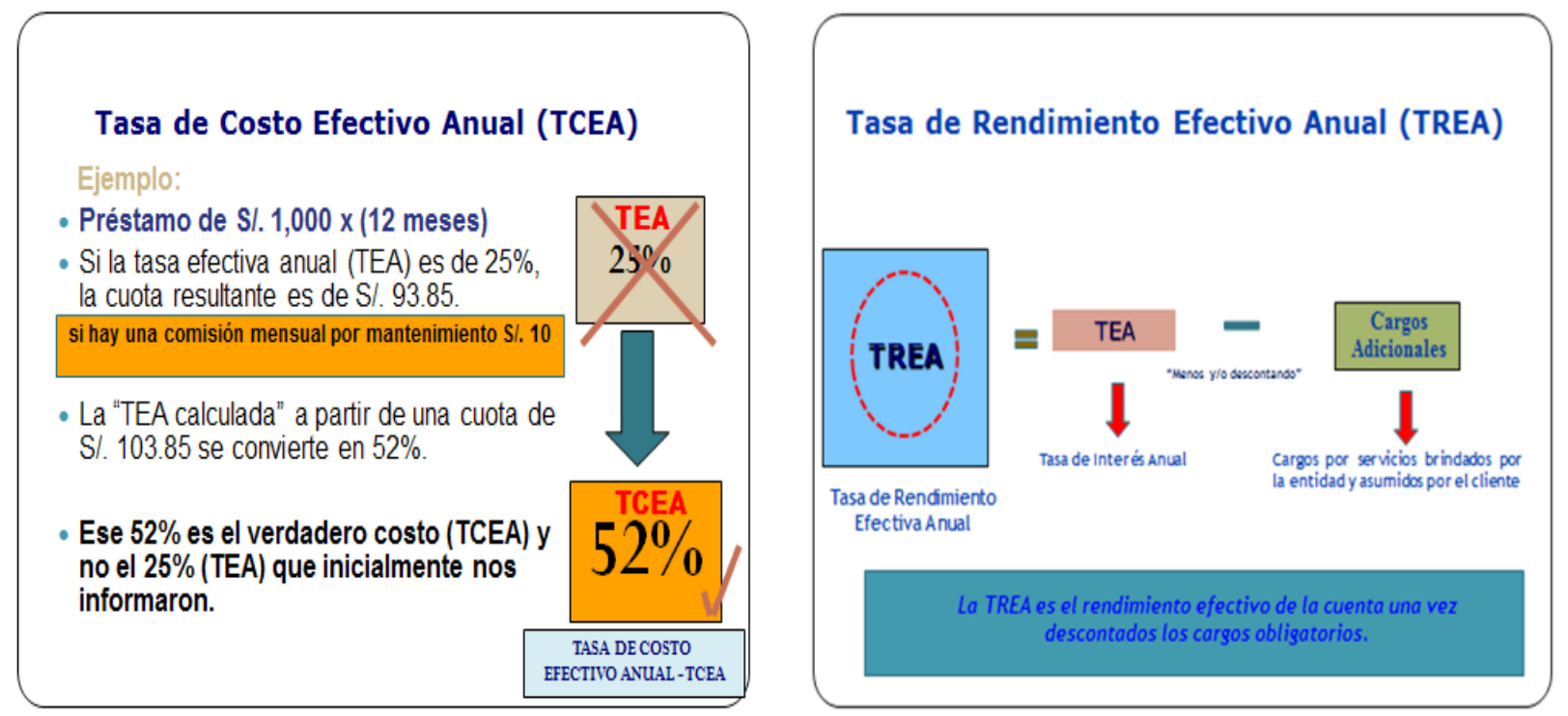

Elaborados por Comisión de Defensa del Consumidor de la gestión 2011-2012.

El dictamen fue aprobado por mayoría en la Comisión de Defensa del Consumidor en su sesión del 10 de abril del 2012, el dictamen acumuló los Proyectos de Ley 809/2011CR y $810 / 2011$ CR con un texto sustitutorio que modificaba los artículos 82, 83, 84 y 94 del Código de Protección y Defensa del Consumidor, Ley 29571 y los artículos 2, 5 y 6 de la Ley Complementaria a la Ley de Protección al Consumidor en materia de Servicios Financieros, Ley 28587.

El dictamen pretendió corregir esta situación con una fórmula que establecía que cada vez que se anuncien créditos revolventes o tarjetas de crédito, se informe, bajo unos supuestos establecidos por la Superintendencia de Banca,
Seguros y AFP's cuál es la TCEA es decir la Tasa de Costo Efectivo Anual.

El 23 de Mayo de 2012 el dictamen fue puesto en debate y contaba con opiniones favorables del Banco Central de Reserva, el Indecopi y la Superintendencia de Banca, Seguros y AFP's; la Asociación de Bancos del Perú (Asbanc) tuvo algunas observaciones que fueron escuchadas por la Comisión.

Asbanc señalaba que la TCEA y la TREA no pueden difundirse en todos los medios de información ya que hay soportes, como el tarifario, en los cuales no es posible entregar dicha información; la Comisión consideró que este es un principio general para promover la difusión de la TCEA y TREA como costo y rendimiento real en las operaciones activas y pasivas, respectivamente. En las situaciones descritas por ASBANC se reconoce la facultad de la SBS para regular esta información y la forma como se difunde al público.

Asbanc indicó que el Reglamento de Transparencia regula la información que debe incluirse en la publicidad, según su contenido sea de carácter cuantitativo o cualitativo, variando la difusión de la TCEA y TREA en función a ello. La Comisión consideró que el Reglamento de Transparencia no regula el contenido de la publicidad, reconociendo que ésta se rige por el Código, sólo lo hace respecto de los folletos informativos que se distribuyen en las oficinas de 
atención al público. En los artículos $82^{\circ}$ y $83^{\circ}$ referidos a la publicidad de operaciones activas y pasivas, se establece la obligación de difundir la TCEA y TREA sólo si el contenido de la publicidad incluye información de carácter cuantitativo (tasas de interés activa o pasiva, monto o cuota).

También se argumentó que la difusión de una TCEA para consumos bajo la modalidad revolvente se basa en la aplicación de supuestos hipotéticos ajenos a cada realidad de consumo por lo cual su aplicación podría generar confusión. La Comisión consideró que el Código señala que la TCEA para modalidad revolvente se calculará sobre la base de un patrón estandarizado de comparación de costos que determine la SBS. Cabe destacar, que la TREA también es un valor referencial ya que no es calculado según las características de cada depósito, pero permite orientar al consumidor respecto del rendimiento a obtener y a la fecha no habría generado confusión, por el contrario, ha permitido fungir de herramienta adicional para difundir información relevante antes de la contratación.

El dictamen debatido también planteaba una modificación de los créditos a plazo fijo y a los créditos hipotecarios, en cuanto a que cuando se hayan pactado un interés, éste no podía ser modificado de manera unilateral. En un crédito revolvente y en una tarjeta de crédito los intereses sí pueden modificarse, por que las personas tienen trato sucesivo con el banco y, de pronto, por las coyunturas económicas, éste último puede comunicar que va a reajustar las tasas de interés; Sin embargo si se trata de un crédito hipotecario a largo plazo con una cuota fija, el banco no puede alterar las condiciones pactadas, pero se reconoce que en los últimos años, aunque los banco hayan tenido la capacidad de modificar los contratos de forma unilateral, ello no ha sucedido, tal como lo reconoció en el debate el entonces presidente de la Comisión de Defensa del Consumidor, ${ }^{4}$ en la sesión plenaria del 23 de mayo de 2012.

En la misma sesión se introdujeron cambios al texto sustitutorio del dictamen en lo referente a la publicidad de los productos o servicios donde debe incluirse la información de la tasa final, la precisión del legislador ${ }^{5}$ fue incluir información sobre la tasa final cuando tenga por finalidad ofrecer los productos, porque puede suceder que se esté informando sobre otros aspec- tos. Una segunda precisión fue la de establecer que ante un conflicto o discrepancia entre las normas relativas a la defensa del consumidor las disposiciones no afectan las condiciones más favorables establecidas a favor del usuario y una tercera y última precisión que también fuera aceptada en el debate fue que en casos excepcionales como una crisis internacional la Superintendencia de Banca, Seguros y AFP's (SBS), previo informe del Banco Central de Reserva, podrá autorizar la variación de las tasas al sistema financiero en general por circunstancias extraordinarias e imprevisibles que pongan en riesgo el propio sistema y conforme a los parámetros que establezca para dicho efecto.

En el debate en la sesión plenaria se planteó una cuestión previa para que regrese a las comisiones de Defensa del Consumidor y de Economía, propuesta que fue rechazada, luego de lo cual se votó el texto de la Comisión de Defensa del Consumidor con los agregados que proponía el dictamen de la Comisión de Economía, la votación resultó con el voto aprobatorio de 61 parlamentarios a favor, 8 en contra y 26 abstenciones; también fue exonerado de segunda votación por mayoría. 

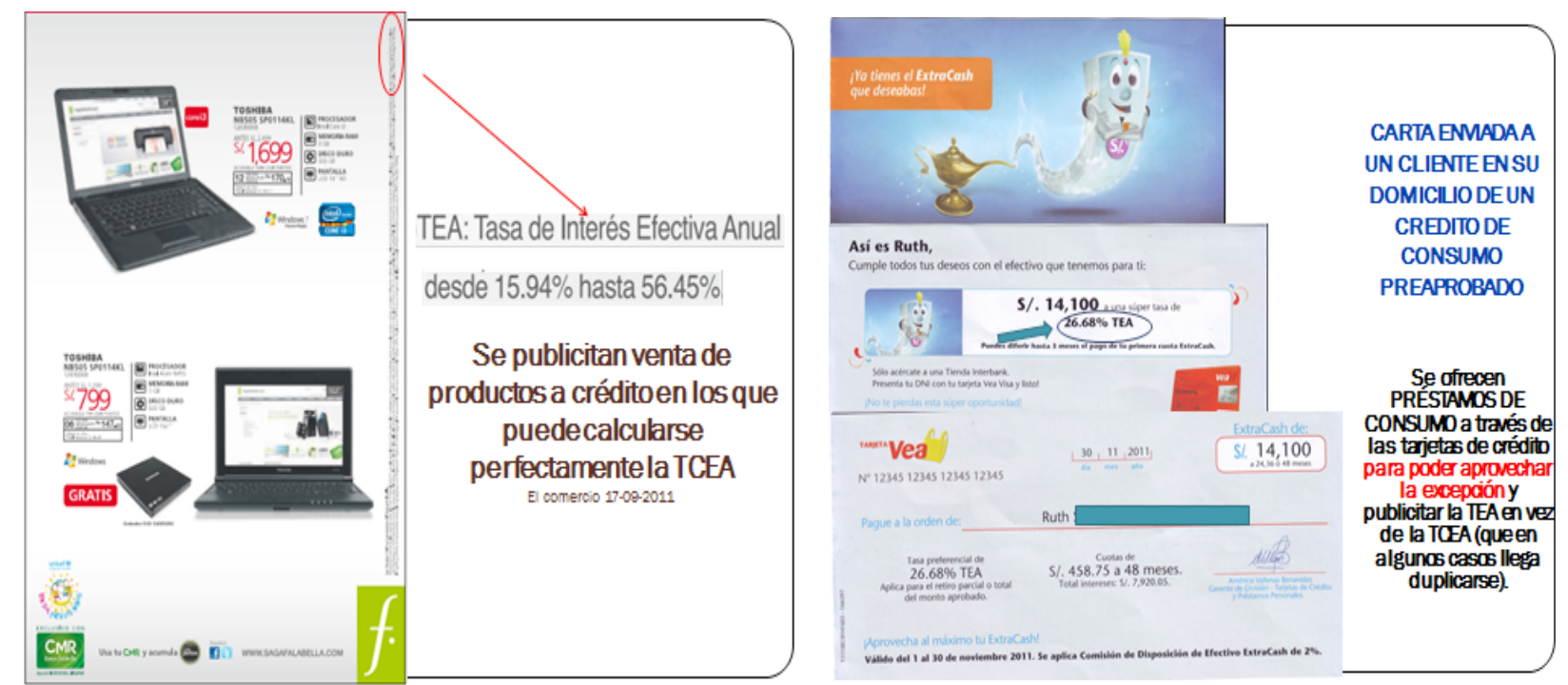

Data: Publicado por las empresas

Elaborados por Comisión de Defensa del Consumidor de la gestión 2011-2012.

La Ley 29888 fue publicada el 24 de junio de 2012 y modificó 4 artículos del capítulo de servicios financieros del Código de Protección y Defensa del Consumidor; referidos a la transparencia en la información de los productos o servicios financieros.

A partir de la dación de la norma:

"Los proveedores de servicios financieros están obligados a difundir y otorgar a los consumidores o usuarios, en todos los medios empleados que tengan por finalidad ofrecer productos o servicios, incluyendo el presencial, información clara y destacada de la tasa de costo efectivo anual (TCEA) y la tasa de rendimiento efectivo anual (TREA), aplicable a las operaciones activas o pasivas, respectivamente. En caso de que el consumidor o usuario solicite o se le otorgue información de forma oral, debe indicarse las mencionadas tasas.

La TCEA es aquella tasa que permite igualar el valor actual de todas las cuotas y demás pagos que serán efectuados por el cliente con el monto que efectivamente ha recibido del préstamo y la TREA es aquella tasa que permite igualar el monto que se ha depositado con el valor actual del monto que efectivamente se recibe al vencimiento.

La TCEA y la TREA deben comprender tanto la tasa de interés como todos los costos directos e indirectos que influyan en su determinación.

La TCEA, en el caso de operaciones bajo el sistema de cuotas, corresponde al costo del crédito; y, en el caso de créditos otorgados bajo el sistema revolvente, atendiendo a sus características, a un patrón estan- darizado de comparación de costos del producto.

La TREA, en el caso de depósitos a plazo fijo, corresponde al rendimiento del depósito realizado; y, en el caso de depósitos distintos al previamente indicado, a un patrón estandarizado de comparación de rendimiento del producto.

La TCEA y TREA se presentan de acuerdo a los parámetros que para tal efecto fije la Superintendencia de Banca, Seguros y Administradoras Privadas de Fondos de Pensiones.

La Superintendencia regula la información que las instituciones financieras deben proporcionar al consumidor o usuario en cualquier operación que conlleve el cobro de intereses, comisiones y gastos y la forma en que dicha información debe ser presentada a lo largo de toda la relación contractual"'.

\footnotetext{
$6 \quad$ Artículo 82 modificado por la Ley 29888.
} 
Respecto de la publicidad se estableció que:

"En los productos o servicios financieros de crédito que anuncien tasas de interés activa, monto o cuota, el proveedor debe consignar de manera clara y destacada la tasa de costo efectivo anual (TCEA) calculada para un año de trescientos sesenta (360) días y presentada conforme a los parámetros que para tal efecto establezca la Superintendencia de Banca, Seguros y Administradoras Privadas de Fondos de Pensiones, de acuerdo con lo dispuesto en el artículo 82 del presente código.

No está permitido, bajo ninguna denominación, hacer referencia a tasas de interés distintas a la indicada en el cuerpo principal del anuncio, las que podrán incluirse en las notas explicativas, en caso de que corresponda $a^{7}$.

En la publicidad de productos o servicios financieros pasivos, que anuncien tasas de interés pasivas, el proveedor debe anunciar la tasa de rendimiento efectivo anual (TREA) calculada para un año de trescientos sesenta (360) días.

No está permitido, bajo ninguna denominación, hacer referencia a tasas de interés distintas a la indicada en el cuerpo principal del anuncio, las que podrán incluirse en las notas explicativas, en caso de que corresponda.
Las empresas del sistema financiero no pueden denominar $a$ un producto $o$ servicio financiero pasivo como "libre" o "sin costo", o presentar algún otro término que implique gratuidad si bajo algún supuesto es posible que se trasladen conceptos a los consumidores como cargos por mantenimiento, actividad $u$ otros.

Respecto de la determinación de las tasas de interés, los proveedores deben presentar la tasa de costo efectivo anual (TCEA), de acuerdo con los parámetros que para tal efecto establezca la Superintendencia de Banca, Seguros y Administradoras Privadas de Fondos de Pensiones, en concordancia con lo dispuesto en el artículo $82 \mathrm{del}$ presente código.

En caso de que los proveedores diferencien el precio del producto o servicio, o se establezcan promociones o rebajas en función del medio de pago o forma de financiamiento otorgado por una empresa supervisada o no, la TCEA debe calcularse exclusivamente sobre el precio al contado, en efectivo o cualquier otra definición similar, del producto o servicio ofertado".

Así mismo la ley modifica la Ley Complementaria a la Ley de Protección al Consumidor en materia de Servicios Financieros en cuanto a transparencia en la información para que la información que proporcionen considere aquellos aspectos relevantes relacionados principalmente a los beneficios, riesgos y condiciones del producto o servicio financiero que se ofrece en el mercado, conforme la regulación emitida por la Superintendencia de Banca, Seguros y Administradora de Fondo de Pensiones. La mencionada obligación se satisface con la puesta a disposición de los usuarios de dicha información en todos los medios utilizados para informar respecto a sus productos o servicios. Las empresas deben designar personal especializado para brindar asesoría a sus clientes sobre los alcances de los mismos.

La Ley amplía el plazo de 45 días en lugar de 15, para que se sean notificados a los usuarios, las modificaciones contractuales, de intereses pactados y de cronogramas de pago efectuadas en forma unilateral por las entidades bancarias y financieras.

\section{LA SEGUNDA MODIFI- CATORIA: GARANTÍA DE PROTECCIÓN EN SERVICIO DE TRANSPORTE EN TRAMOS MÚLTIPLES}

En el mercado aéreo se comercializan dos tipos de productos: (i) One way (origen-destino o sólo ida) y (ii) Round Trip sobre los vuelos Round Trip, la Ley 30046, "Ley que Protege al Usuario del Servicio de Transporte en Tramos Múltiples", la cual se emitió como consecuencia de las restricciones que se efectuaron en los boletos de tramos múltiples o de ida y vuelta referidas a: "obligar al pasajero a hacer uso obligatorio del primer tramo del billete ya

Artículo 83 modificado por la Ley 29888. 
que de no utilizarse el tramo de ida, la empresa procedía a anular de manera automática el tramo de regreso". Situación que consistía por ejemplo: en que si un usuario tenía un pasaje Lima-Chiclayo-Lima y por cualquier circunstancia, a veces un caso fortuito o de fuerza mayor, no volaba el primer tramo, (Lima-Chiclayo) la empresa anulaba automáticamente el ticket de regreso (Chiclayo-Lima).

Algunas empresas de transporte de pasajeros y específicamente aerolíneas ofrecían promociones de boletos de ida y vuelta o de tramos múltiples, con la característica de que si por algún motivo el consumidor no puede utilizar el boleto de ida o uno de los tramos, automáticamente pierde la posibilidad de utilizar el boleto de regreso o el resto de tramos.

El Proyecto de Ley $1524 / 2011$ CR $^{8}$ propuso incorporar un segundo párrafo al artículo 66 del Código para que cuando se trate de boletos de ida y vuelta o boletos para destinos o tramos múltiples, el proveedor no pueda dejar sin efecto el boleto de vuelta si es que el consumidor no utiliza el boleto de ida; asimismo, para estos boletos también operaría la condición establecida en el primer párrafo del artículo 66.7 del código con relación al endoso o transferencia de la titularidad del servicio adquirido.

Eran clausulas establecidas por las empresas de transporte que tenían el siguiente tenor:
“2.9 los vuelos o tramos que componen el itinerario deberán volarse en el orden consecutivo indicado. el transportista, sujeto a las condiciones previstas en la legislación aplicable, podrá negar el embarque a un pasajero que no cumpla con el orden del itinerario antes referido o si el pasajero no ha volado alguno de los tramos indicados en su pasaje. el pasajero entiende que si no se vuela alguno de los tramos indicados en el itinerario, éste se cancelará en su totalidad, sin previo aviso, no procediendo ningún tipo de reembolso."

La negrita y subrayado es nuestro.

Si bien los proveedores, en ejercicio de su libertad empresarial, reconocida en la Constitución, pueden crear y ofrecer a los consumidores los productos y servicios que consideren convenientes, es deber del Estado que esta oferta se realice en concordancia con los derechos de los consumidores.

El código establecía que las cláusulas contenidas en los contratos de consumo por adhesión deben ser redactadas bajo el principio de la buena fe y del equilibrio necesario en los derechos y obligaciones de las partes 9

En el debate, se pidió $^{10}$ se incluya un párrafo para evitar la posibilidad de abuso de determinadas personas, que no es el consumidor al que se quiere proteger sino otro. Por ello se aceptó el agregado "que el consumidor cuente con otra reserva o boleto para la misma ruta entre las fechas comprendidas en el boleto cuyo tramo desea preservar". Para dejar claro que una sola persona compre 20 3 tramos y juegue con las opciones y se genere algún tipo de abuso.

El dictamen fue aprobado por la Comisión por mayoría en la décimo cuarta sesión ordinaria del 26 de marzo del 2013 sustentando que, siguiendo los preceptos que establece el Código, debe tenerse en cuenta que cuando un consumidor adquiere un boleto de ida y vuelta ha realizado un pago ambos tramos, cada uno de los cuales se encuentran debidamente identificados e individualizados, y conforme a ello, adquirió el derecho de viajar tanto de ida como de regreso al destino deseado.

La Comisión consideró que el hecho de que un consumidor no se presente a abordar al vuelo de ida o a uno de los tramos no implica que no lo hará tampoco en el vuelo de regreso o al tramo siguiente, suponer ello implicaría desconocer que existen diversos motivos, incluso involuntarios, por los cuales un consumidor no se presenta al abordaje y que ello no impide que tome otras vías para llegar al destino y sin problemas abordar el tramo siguiente o vuelto de retorno, por el cual ya ha realizado el pago respectivo.

\footnotetext{
Presentado por el Congresista José Luna Gálvez

Artículo 48 inciso c de la Ley 29571, Código de Protección y Defensa del Consumidor.

10 A solicitud del Congresista Luis Galarreta Velarde
} 
En ese sentido el dictamen reconoce que si un consumidor ha realizado un pago por boletos tanto de ida como de retorno o por varios tramos, no existe razón para desconocer el pago realizado por cada uno de los tramos y, ante la falta de abordaje del primero, restringir el acceso a los demás tramos programados.

Respecto a la situación que ante una omisión de abordaje del vuelo de ida o primer tramo, las empresas tienen la oportunidad de vender nuevamente el asiento reservado en los tramos siguientes.

En el debate el legislador autor de la propuesta ${ }^{11}$ sustentó que cuando los proveedores vuelven a vender el asiento prácticamente están percibiendo un doble ingreso por un mismo espacio en el vuelo lo cual no puede colocarse por encima del derecho de los consumidores a acceder a un servicio por el que ya pagaron. Consideró que no se afectaría a los proveedores, puesto que se trata simplemente de la prestación de un servicio por la que el consumidor ya realizó el pago y que la empresa está en condiciones de brindar, es decir, el consumidor adquirió el derecho de viajar tanto de ida como de regreso al destino deseado.

Otro de los argumentos esbozados para la aprobación en la Comisión fue que la modificación no acarrearía mayor perjuicio económico a los proveedores quienes se limitarían a prestar un servicio por el cual el consumidor ya realizó la contraprestación, pero sí corregiría la situación actual que vienen atravesando los consumidores, quienes ante la pérdida de un vuelo, se ven obligados a adquirir nuevamente boletos no solo de ida, sino también de retorno, pese a que éste último se encuentra aún vigente y pasible de ser abordado en su oportunidad por el consumidor.

Otro de los argumentos de fuerza que se esbozaron y forman parte del dictamen fue que éste tipo de prácticas ya han sido prohibidas por los tribunales de países como España, a través de sentencias emitidas el 3 de julio 2009 y el 22 de marzo de 2010 por el Juzgado de lo Mercantil de Bilbao y el juzgado de lo Mercantil 2 de Palma de Mallorca, que señaló:

“... este tipo de cláusulas son abusivas al permitir hacer doble venta del mismo asiento, dificultando al pasajero hacer uso de su derecho a utilizar todos los trayectos adquiridos."

Respecto del perjuicio a los proveedores menciona la misma sentencia:

“... el pasajero es libre de
adquirir los billetes que
tenga por convenientes,
haciendo uso de los mismos
o no, puesto que una vez
pagado el precio, no irroga
ningún perjuicio al trans-
portista al no presentarse
para el embarque."

“... el pasajero es libre de adquirir los billetes que tenga por convenientes, haciendo uso de los mismos o no, puesto que una vez pagado el precio, no irroga ningún perjuicio al transpara el embarque."
Finalmente, si bien los proveedores, en ejercicio de su libertad empresarial pueden crear $\mathrm{y}$ ofrecer a los consumidores los productos y servicios que consideren convenientes, es deber del Estado el de garantizar que las condiciones en las que dichos servicios son ofrecidos sean de equilibrio en la relación consumidor-proveedor. Por ello que las cláusulas contenidas en los contratos de consumo por adhesión no deben colocar al consumidor en una situación de desventaja o desigualdad.

El debate en el Pleno del Congreso de la República se realizó el 16 de mayo de 2013 y en general tuvo el apoyo de diversas bancadas, salvo 4 votos en contra y 6 abstenciones fue aprobado por la mayoría de los legisladores ${ }^{12}$.

Fue finalmente publicada la Ley 30046 el 20 de junio del 2013 y entre los alcances y trascendencia de la modificatoria destacan que la Ley 30046 beneficiosa para los usuarios de transporte en general y particularmente de los pasajeros del servicio aéreo, pues las empresas de todo tipo de transporte, ya no podrán incluir en sus boletos o ticket la cláusula abusiva carente de justificación por la cual dejaban sin efecto el boleto de regreso cuando el pasajero no había hecho uso del boleto de ida.

La ley establece que queda prohibido que los proveedores dejen sin efecto este derecho. La única razón por la cual la empresa podría dejar sin efecto

11 Congresista José Luna Gálvez

12 El Proyecto de Ley 3969/2014-CR, presentado por el Grupo Parlamentario Unión Regional a iniciativa del congresista Marco Tulio Falconí Picardo que propone la ley que establece la independencia de los tramos y el sinceramiento del costo de los boletos de viaje. 
éste derecho será cuando el pasajero tenga otra reserva o boleto en la misma empresa para la misma ruta y la misma fecha.

En el Periodo Anual de Sesiones 2015-2016 entró en debate otro Proyecto de Ley $^{13}$ que pretendía aclarar esta modificatoria que finalmente fue dictaminado a favor por la Comisión de Defensa del Consumidor, pero nunca llegó a debatirse en el Pleno. En líneas generales pretendía aclarar que cuando se adquiera boletos de ida y vuelta o para destinos o tramos múltiples, el proveedor no puede dejar sin efecto el boleto de ida o de vuelta, aun cuando el consumidor postergó o cedió el boleto, además de buscar especificar independencia de la prestación en los tramos en un pasaje round trip.

El INDECOPI se ha pronunciado en la Resolución $N^{\circ}$ 2033-
2014/SPC-INDECOPI del 23 de junio de 2014 enfatizando que el ejercicio de postergar un vuelo, cualquiera sea la modalidad del servicio, debe efectuarse 24 horas antes de la salida del vuelo de ida o de la del vuelo de retorno.

Para ello, la Sala Especializada de Protección al Consumidor del INDECOPI que si bien la modalidad "round trip" implica la prestación de un servicio asentado sobre la base de una oferta contractual unitaria que permite a los consumidores adquirir pasajes de ida y vuelta. Su puesta en práctica supone la ejecución de dos prestaciones independientes, constituidas precisamente por el transporte de ida y el de regreso. De modo que, la legitimidad del ejercicio del derecho de postergación puede ser ejercida con una anticipación de 24 horas, en cualquiera de los tramos, ya sea el de ida o de regreso. (El resaltado y subrayado es nuestro).

\section{DictámENES QUE PRE- TENDIERON MODIFICAR EL CÓDIGO, PERO QUE NO SE DEBATIERON EN EL PLENO Del PERIOdo PARLAMEN- TARIO 2011-2016}

Se presentaron varios proyectos de ley que pretendieron modificar el Código en el último quinquenio, nos ocuparemos en el presente artículo sólo de aquellos que fueron analizados y debatidos en la Comisión de Defensa del Consumidor y que finalmente se convirtieron en dictámenes que quedaron listos para ser agendados en las sesiones plenarias.

Fueron 5 dictámenes que acumularon 13 proyectos de ley los que pretendieron modificar el Código en el último quinquenio 2011-2016, conforme el cuadro siguiente:

\begin{tabular}{|c|c|c|}
\hline Proyectos de Ley & Sumilla & $\begin{array}{l}\text { Fecha de } \\
\text { dictamen }\end{array}$ \\
\hline $\begin{array}{l}\text { 57/2011-CR; } 2103 / 2012-C R ; \\
2181 / 2012-C R \text { y 26/2013-CR }\end{array}$ & $\begin{array}{l}\text { Incorpora el numeral } 4 \text { al artículo III del } \\
\text { TP y modifica los artículos } 24,44,104 \text { y } \\
152 \text { del Código. Libro de reclamaciones }\end{array}$ & $\begin{array}{l}13 \text { de mayo de } \\
2014\end{array}$ \\
\hline $3447 / 2014-C R$ y $3794 / 2014-C R$ & $\begin{array}{c}\text { Incorpora el artículo 90A al Código, para } \\
\text { garantizar el derecho de libre elección } \\
\text { del servicio notarial }\end{array}$ & $\begin{array}{c}18 \text { de Noviembre } \\
\text { de } 2014\end{array}$ \\
\hline $4170 / 2013 C R$ y $4240 / 2013 C R$ & $\begin{array}{c}\text { Modificación de los artículos } 76,77 \text { y } 78 \\
\text { del Código para fortalecer la protección } \\
\text { del consumidor de bienes y servicios in- } \\
\text { mobiliarios }\end{array}$ & $\begin{array}{l}19 \text { de mayo de } \\
2015\end{array}$ \\
\hline $\begin{array}{l}\text { 1847/2012-CR; 3969/2014-CR; } \\
\text { 4040/2014-CR y 4297/2014-CR }\end{array}$ & $\begin{array}{l}\text { Modificación del artículo } 66 \text { del código } \\
\text { para fortalecer la protección del usuario } \\
\text { del servicio de transporte }\end{array}$ & $\begin{array}{c}03 \text { de noviembre } \\
\text { de } 2015\end{array}$ \\
\hline $1991 / 2012-C R$ & $\begin{array}{l}\text { Adición del artículo 147A al Código para } \\
\text { regular la asistencia a la audiencia de } \\
\text { conciliación de consumo }\end{array}$ & $\begin{array}{c}24 \text { de noviembre } \\
\text { de } 2015\end{array}$ \\
\hline
\end{tabular}

Elaboración propia. 
Detallamos el contenido de los 5 dictámenes que en cierta manera quedan como tarea pendiente para ser evaluados por los legisladores del quinquenio 2016-2021.

\subsection{Modificaciones al Libro de Reclamaciones}

El 13 de mayo del 2014 la Comisión aprobó por unanimidad la modificación de los artículos 24.1, 150 y 152 de la Ley 29571 de la Ley 29571 Código de Protección y Defensa del Consumidor, en los siguientes términos:

\begin{abstract}
"Artículo 24.- Servicio de atención de reclamos:

24.1 Sin perjuicio del derecho de los consumidores de iniciar las acciones correspondientes ante las autoridades competentes, los proveedores están obligados a atender los reclamos presentados por sus consumidores y dar respuesta a los mismos en un plazo no mayor de quince (15) días calendario. Dicho plazo puede extenderse hasta por 7 días calendario adicionales y por única vez, cuando la naturaleza del reclamo lo justifique, situación que debe ponerse en conocimiento del consumidor antes de la culminación del plazo inicial ${ }^{13}$ ".
\end{abstract}

Con ello los consumidores podrían exigir que en no más de 15 días los proveedores den respuestas a los reclamos que presenten ya sea en el Libro de Reclamaciones o en otros tipos de procedimientos que tenga la empresa reclamada (como el llamado código de reclamo). Sólo se podría prorrogar excepcionalmente el plazo una sola vez y por 7 días más, es decir que como máximo los proveedores hubiesen tenido 21 días para dar respuesta al consumidor. El dictamen señaló que se trata de días calendarios que incluye sábados y domingos.

También se propuso la modificación del artículo 150 sobre el Libro de Reclamaciones, quedando redactado de la siguiente manera:

\section{"Artículo 150. - Libro de Re- clamaciones:}

Los establecimientos comerciales y los titulares de las instalaciones ubicadas al interior de un establecimiento comercial abierto al público que se presenten como establecimientos independientes (stand, boutique, tiendas y similares) deben contar con un libro de reclamaciones, sea de naturaleza física o virtual en cada uno de sus locales, el cual debe ser puesto inmediatamente a disposición del consumidor cuando lo solicite.

150.1 El proveedor que utiliza medios virtuales para establecer sus relaciones de consumo, deberá también implementar un libro de reclamaciones virtual alojado en la página de inicio de su portal web, el mismo que debe estar actualizado para permitir al consumidor el seguimiento de su reclamo o queja y además brindarán la asistencia personalizada al consumidor que solicite ingresar su queja o reclamo en el Libro de Reclamaciones en cada uno de sus establecimientos.

150.2 El proveedor de servicios de transporte debe poner a disposición el Libro de Reclamaciones en las áreas de embarque, desembarque en los que preste algún servicio a los usuarios. El proveedor de servicio de trasporte aéreo, marítimo y fluvial también pondrá a disposición del usuario el Libro de Reclamaciones en sus aeronaves y unidades de flota respectivamente.

El reglamento establece las condiciones, los supuestos y las demás especificaciones para el cumplimiento de la obligación señalada en el presente artículo ${ }^{14 "}$.

Con la modificación señalada la Comisión buscó que el Libro de Reclamaciones sea más efectivo, y quiso desterrar la idea que sea un libro de anotaciones de quejas o reclamos; se quiso rescatar el verdadero objeto del libro y tal como fue concebido en el Código, para que el proveedor corrija en el mismo acto algún mal servicio o productos defectuosos y de solución inmediata a la queja o reclamo del consumidor eli-

\footnotetext{
13 Dictamen de los Proyectos de Ley 57/2011-CR; 2103/2012-CR; 2181/2012-CR y 26/2013-CR de la Comisión de Defensa del Consumidor y Organismos Reguladores de los Servicios Públicos.

14 Dictamen de los Proyectos de Ley 57/2011-CR; 2103/2012-CR; 2181/2012-CR y 26/2013-CR de la Comisión de Defensa del Consumidor y Organismos Reguladores de los Servicios Públicos
} 
minando todo futuro conflicto, era pues una herramienta disuasiva para eliminar futuros conflictos.

El dictamen elevaba a rango de Ley las últimas modificaciones hechas al Reglamento del Libro de Reclamaciones por parte del Indecopi, que incluyó a los stands, boutique, tiendas y similares que se encuentran dentro de Centros Comerciales, aeropuertos, estaciones terrestres, etc. están obligados a tener también el Libro de Reclamaciones.

También se señala que si el proveedor es virtual (es decir vende a través del internet) tiene la obligación de tener también el libro de reclamaciones virtual en su página web y debe asistir al consumidor para que este pueda obtener copia de su reclamo.

Se establece que en las áreas de embarque y desembarque y hasta durante el viaje el consumidor tenga la posibilidad de tener el Libro para registrar su queja o reclamo.

También se modificaba el artículo 151 señalando que además del aviso en los establecimientos comerciales de la existencia del Código deberían difundirse a nivel nacional los derechos de los consumidores que contiene el Código.

Unamodificaciónimportantede resaltar fue la del artículo 152:

“Artículo $152^{\circ}$.- Entrega de información al INDECOPI

Los consumidores pueden exigir la entrega del Li- bro de Reclamaciones para formular su queja o reclamo respecto de los productos o servicios ofertados. Los establecimientos comerciales tienen la obligación de remitir al Indecopi la copia de la queja o reclamo que contenga las acciones adoptadas por el proveedor o sus descargos en el plazo de 7 días útiles de formulada, con la cual el Indecopi podrá iniciar de oficio el procedimiento sancionador de considerarlo pertinente. Toda la información correspondiente al libro de reclamaciones recibida por Indecopi será procesada y publicada en su página web a través de un Sistema de Reporte de Reclamaciones creado para éste fin. El reglamento establece las condiciones, los supuestos y las demás especificaciones para el cumplimiento de la obligación señalada en el presente artículo".

Se buscaba hacer más efectivo el Libro de Reclamaciones pues el Indecopi tendría la copia de la queja o reclamo y las acciones adoptadas por el proveedor o sus descargos en el plazo de 7 días útiles de formulada la queja o reclamo, con la cual el Indecopi podrá iniciar de oficio el procedimiento sancionador de considerarlo pertinente.

Toda la información correspondiente al libro de reclamaciones recibida por Indecopi sería procesada y publicada en su página web a través de un Sistema de Reporte de Reclamaciones que ya existe.

\subsection{Garantizar el derecho de libre elección del servi- cio notarial}

Se aprobó por mayoría en la séptima sesión ordinaria del 18 de noviembre de 2014, El dictamen acumula los Proyectos de Ley 3447/2013-CP y $3794 / 2014-$ CR $^{15}$ respectivamente con un texto sustitutorio que propone la Ley que modifica la Ley 29571, Código de Protección y Defensa del Consumidor, para garantizar el derecho de libre elección del servicio notarial.

El dictamen se ocupa de la actual problemática que sufren los consumidores o usuarios de servicios financieros, aquellos que constituyen hipotecas o prendas a consecuencia de un crédito bancario o financiero, y son direccionados o condicionados por las empresas financieras que les otorgaron el préstamo a contratar con determinado notario que de fe de sus actos contractuales.

La Comisión consideró que el derecho de elección no estaría garantizada con el artículo 21 de la Resolución SBS 8181, Reglamento de Transferencia de Información, pues el banco está obligado a publicar una lista con los notarios con los que trabaja, la elección recae en el banco y no en el usuario. Luego del debate se aprobó por mayoría el Dictamen que incorpora el artículo $90 \mathrm{~A}$ en la Ley 29571, y dejó sin efecto el artículo 21 del Reglamento de Transparencia de Información y Contratación con Usuarios del Sistema Financiero, aprobado por Resolución SBS 81812012.

15 Iniciativas del Colegio de Notarios de Lima y de la congresista Esther Capuñay, respectivamente. 
"Artículo 90 A. Libre elección de los servicios notariales en la contratación de servicios financieros

1. El Estado garantiza el derecho del ciudadano a contratar con el notario de su elección en las condiciones de seguridad e infraestructura previstas en el presente artículo.

2. En las transferencias de bienes o derechos financiados por empresas del sistema financiero así como en los supuestos de contratación financiera o bancaria, el derecho de libre elección del notario corresponde al adquirente o cliente de la entidad bancaria o financiera.

3. Para el cumplimiento de la presente disposición, la entidad bancaria o financiera proporciona al usuario, copia simple de los documentos registrales en los que consten las facultades de sus funcionarios o apoderados autorizados a suscribir los documentos públicos y privados a nombre de estas.

4. El notario elegido cuenta con herramientas $e$ infraestructura física y tecnológica para identificar a los intervinientes, acceder a la información registral sobre los bienes, derechos 0 personas involucradas y facilitar la comunicación con la entidad financiera o bancaria y los clientes. Estas herramientas son: Servicio de Verificación Biométrica (SVB) para consultas en línea del Registro Nacional de Identificación y Estado Civil (Reniec).

a) Servicio de Publicidad Registral en Línea de la Superintendencia Nacional de los Registros Públicos (Sunarp).

b) Sistema de identificación de extranjeros.

c) Dirección electrónica corporativa.

d) Personal de atención al cliente bajo la conducción de abogado colegiado.

e) La publicación en su oficio notarial y/o página Web de los requisitos necesarios para el trámite notarial, del tiempo aproximado estimado de atención, y la tarifa de sus servicios notariales.

Las entidades financieras $o$ bancarias deben otorgar las facilidades al notario elegido para que los funcionarios o representantes de aquellas puedan suscribir oportunamente los instrumentos públicos notariales".

\subsection{Fortalecer la protección del consumidor de bie- nes y servicios inmobi- liarios}

El dictamen ${ }^{16}$ fue aprobado por unanimidad el 19 de mayo de 2015 y modifica los artículos 76; 77, párrafo 77.1, y 78, párrafo 78.1, de la Ley 29571, Código de Protección y Defensa del Consumidor, en los siguientes términos:

"Artículo 76.- Protección del consumidor en contratos inmobiliarios
76.1 En toda la publicidad escrita entregada de manera directa al consumidor, en etapa preliminar, de bien inmueble futuro o de bien inmueble de primer uso cuya entrega de la posesión no se realizaría en el momento de la suscripción del contrato, el proveedor debe consignar la información establecida en el artículo 77.

76.2 El derecho del consumidor a la información obliga al proveedor de productos y servicios inmobiliarios a informar sobre las características del inmueble que está adquiriendo así como a proporcionar toda aquella documentación que acredite la existencia de autorizaciones municipales, el área del inmueble, el proceso de titulación, habilitación urbana, saneamiento, materiales empleados en la construcción y en los acabados, inscripciones registrales del terreno y Declaratoria de Fábrica o de Edificación, reglamento interno, independización y toda aquella documentación relevante.

Artículo 77.- Información mínima en el proceso de compra

77.1 Los proveedores deben establecer $e$ implementar medidas

16 Dictamen de los Proyectos de Ley 4170/2014-CR y 4240/2014-CR a iniciativa de los congresistas Carlos Bruce Montes de Oca y Justiniano Rómulo Apaza Ordóñez respectivamente. 
para brindar, como mínimo, información clara y veraz sobre:

c. Los antecedentes del proveedor y su comportamiento en el mercado de productos y servicios inmobiliarios.

d. La existencia de la Central de Información de Promotores Inmobiliarios y/o Empresas Constructoras de Unidades Inmobiliarias, creada mediante Ley 29203, $y$ del registro de infracciones y sanciones por el incumplimiento de las disposiciones del presente Código a cargo del Instituto Nacional de Defensa de la Competencia y de la Protección de la Propiedad Intelectual (Indecopi), conforme lo establece el artículo 119.

e. Los canales para la atención de quejas, reclamos o denuncias ante las autoridades competentes, debiendo exhibir tal información mediante un aviso colocado en un lugar visible y fácilmente accesible al público. El aviso tiene las mismas dimensiones establecidas para el aviso del Libro de
Reclamaciones al que hace referencia el artículo 151 del presente Código y su reglamento.

Los proveedores deben adoptar medidas para permitir que el consumidor acceda fácilmente a la información señalada en el presente artículo. [...]

Artículo 78.- Información mínima del contrato de compraventa

78. 1 Los proveedores deben establecer, implantar y mantener procedimientos para evidenciar que el contrato sea accesible y contenga como mínimo la siguiente información:

[...]

k. Un anexo que formará parte integrante del contrato, donde se consignen las obligaciones del proveedor y los derechos del consumidor señalados en los artículos 76, $77,78,79$ y 80 . [...] “.

En el proceso de compra los proveedores deben brindar como mínimo información clara y veraz, es decir si tiene quejas o multas del ministerio de vivienda, Así también con esto el comprador podrá conocer que puede gratuitamente acceder a esos registros para revisar el comportamiento de las constructoras, de los agen- tes inmobiliarios y de los corredores inmobiliarios, es decir si tiene reclamos de otros compradores.

Los canales para la atención de quejas, reclamos o denuncias ante las autoridades competentes, deberían exhibir tal información mediante un aviso colocando en un lugar visible. Con esto el comprador podrá conocer que puede recurrir al INDECOPI para hacer valer su derecho como consumidor y lograr solucionar su reclamo.

Se establecía que el contrato de compraventa del bien que no estén terminados aún se deben consignar un anexo que contenga los derechos del consumidor y las obligaciones de los constructores, de los promotores y los agentes inmobiliarios que son reconocidas por el Código.

\subsection{Fortalecer la protección del usuario del servicio de transporte}

Este tema ya lo hemos analizado en el numeral anterior, al analizar la segunda modificatoria del Código.

\subsection{Regular la asistencia a la audiencia de concilia- ción de consumo}

El dictamen ${ }^{17}$ fue aprobado por mayoría el 24 de noviembre de 2015 y adiciona a la Ley 29571, Código de Protección y Defensa del Consumidor el artículo $147 \mathrm{~A}$, con el siguiente texto:

"Artículo 147A. Conse-
cuencias de la inasisten-
cia a la audiencia de con-
ciliación

17 Dictamen del Proyecto de Ley 1991/2012-CR a iniciativa del congresista Agustín Molina Martínez. 
Al proveedor debidamente notificado que no asista a la audiencia de conciliación o que no justifique su inasistencia dentro de las veinticuatro horas de haber sido notificado debidamente se le impone una multa de hasta diez por ciento de una unidad impositiva tributaria (UIT).

A pedido de parte, se señala nuevo día y hora para la audiencia de conciliación, la misma que se realiza dentro de los cinco días hábiles siguientes a la primera invitación.

La inasistencia injustificada del proveedor a la segunda invitación de la audiencia de conciliación da por concluida la conciliación y genera en el procedimiento administrativo la presunción legal relativa de verdad sobre los hechos alegados por el consumidor y su conducta debe ser apreciada al momento de resolverse el procedimiento.

El consumidor reclamante recibe la tercera parte de la multa que se impone al proveedor.

Para apersonarse al procedimiento administrativo, el proveedor debe acreditar el pago de la multa impuesta.

En el caso de que el consumidor reclamante es el que no asiste a la audiencia de conciliación o no hubiera justificado plenamente el motivo de su inasistencia, se considera que ha desistido de su reclamo.
La asistencia a la audiencia de conciliación es de carácter personal, salvo las personas que conforme a la Ley 26887, Ley General de Sociedades, pueden actuar a través de representante. Cuando las partes domicilien en jurisdicciones distintas o el INDECOPI considere apropiado así realizarlo, la audiencia puede realizarse vía telefónica o virtual, debiendo otorgarse a las partes constancia escrita de los resultados.

Para efectos del presente artículo, la Ley 26872, Ley de Conciliación es de aplicación supletoria"

La conciliación es una buena oportunidad para solucionar los conflictos entre empresas y consumidores. Actualmente cuando se cita a la audiencia de conciliación a los proveedores el $18 \%$ no asiste y no permite solucionar los conflictos de consumo.

Obligar al proveedor a que asista a la audiencia de conciliación a escuchar cuál es el reclamo o queja y tenga la oportunidad de proponer una solución. No se le obliga a conciliar, sólo se lo obliga a escuchar al consumidor y si quiere acepta la solución o la rechaza.

Se le obliga multándolo por su inasistencia injustificada con multa de hasta $10 \%$ de la UIT. El consumidor reclamante recibiría la tercera parte de la multa que se impone al proveedor. Esta figura no es nueva en la legislación ya que en México y en Argentina se ha incorporado tiempo atrás y ha fortalecido la institución de la conciliación de consumo.

\section{CONCLUSIONES}

1. El Código de Protección y Defensa del Consumidor ha sido modificado por las Leyes 29888 y 30046 .

2. La Ley 29888, transparentó la información en los productos y servicios financieros, facilitó la comprensión y el análisis de los múltiples conceptos financieros; reconoce el derecho del consumidor financiero a desvincularse libremente, sin estar sujeto a condiciones que limiten irrazonablemente tal derecho, como sería el exigir el pago inmediato de la totalidad del monto financiado, cuando la alteración de las condiciones primigeniamente proyectadas es atribuido exclusivamente al proveedor; estableció reglas claras y precisas que rigen la relación de las financieras y sus clientes desde la etapa de la publicidad hasta el momento de la contratación y posteriores a ella.

3. La Ley 30046, estableció que en caso de que el consumidor adquiera boletos de ida y vuelta o boletos para destinos o tramos múltiples y no hiciera uso de alguno de los tramos, tiene el derecho a utilizar los destinos o tramos siguientes, quedando prohibido que los proveedores dejen sin efecto este derecho. La única razón por la cual la empresa podría dejar sin efecto éste derecho será cuando el pasajero tenga otra reserva o boleto en la misma empresa para la misma ruta y la misma fecha. 
4. La Comisión de Defensa del Consumidor del Congreso de la República dictaminó durante el Periodo Parlamentario 2011-2016 modificaciones al Código que no fueron debatidas en el Pleno y que están referidas a cambios en el Libro de Reclamaciones; instaurar el derecho de libre elección del servicio notarial; fortalecer la protección del consumidor de bienes y servicios inmobiliario; fortalecer la protección del usuario del servicio de transporte y; regular la asistencia del proveedor a la audiencia de conciliación de consumo.

\section{REFERENCIAS BIBLIOGRÁFICAS Y FUENTES CONSULTADAS}

Ley 29571, Código de Protección y Defensa del Consumidor.

Ley 29888, Ley que modifica la ley 29571, código de protección y defensa del consumidor, y la ley 28587, ley complementaria a la ley de protección al consumidor en materia de servicios financieros, sobre transparencia de la información y modificaciones contractuales

Ley 30046, Ley que protege al usuario del servicio de transporte en tramos múltiples
Dictamen recaído en el proyecto de ley 1991/2012CR por el que se propone mediante un texto sustitutorio la ley que modifica la Ley 29571, Código de Protección y Defensa del Consumidor, para regular la asistencia a la audiencia de conciliación de consumo.

Dictamen recaído en los proyectos de ley 4170/2014CR y 4240/2014-CR que propone mediante un texto sustitutorio la ley que modifica la ley 29571, código de protección y defensa del consumidor, para fortalecer la protección del consumidor de bienes y servicios inmobiliarios.

Dictamen recaído en el proyecto de ley 1524/2012CR, con un texto sustitutorio que propone la ley que protege al usuario del servicio de trasporte en tramos múltiples.

Dictamen recaído en los Proyectos de Ley 57/2011-CR, 2103/2012CR, 2181/2012CR, 2641/2013-CR y 2688/2013-CR, con un texto sustitutorio que propone la Ley que modifica la Ley 29571, Código de Protección y Defensa del Consumidor, respecto al plazo de respuesta de los reclamos y el Libro de Reclamaciones.

Dictamen recaído en los Proyectos de Ley $1847 / 2012-C R$, 3969/2014-CR, 4040/2014CR, y 4297/2014-CR, que propone mediante un texto sustitutorio la Ley para fortalecer la protección al usuario del servicio de transporte.

Dictamen acumulado recaído en el Proyecto de Ley $\mathrm{N}^{\circ}$ 809/2011-CR, sobre modificaciones al Código de Protección y Defensa del Consumidor; y en el Proyecto de Ley $N^{\circ} 810 / 2011$ CR, sobre modificaciones a la Ley $N^{\circ}$ 28587, Ley Complementaria a la Ley de Protección al Consumidor en materia de Servicios Financieros.

Dictamen en mayoría recaído en los proyectos de ley 3447/2013-CP y $3794 / 2014-C R$ por el que se propone mediante un texto sustitutorio la Ley que modifica la Ley 29571, Código de Protección y Defensa del Consumidor, para garantizar el derecho de libre elección del servicio notarial.

Diario de los Debates del Pleno extraído de: http://www. congreso.gob.pe/Diariodelosdebates/ 
